\section{nephron \\ Clinical}

Practice
Nephron 2018;140:144-147

DOI: $10.1159 / 000490807$
Received: May 15, 2018

Accepted after revision: June 6, 2018 Published online: June 29, 2018

\title{
Cell Death Pathways Drive Necroinflammation during Acute Kidney Injury
}

\author{
Anne von Mässenhausen Wulf Tonnus Andreas Linkermann \\ Division of Nephrology, Department of Internal Medicine III, University Hospital Carl Gustav Carus at \\ the Technische Universität Dresden, Dresden, Germany
}

\section{Keywords}

Necroptosis · Ferroptosis · Pyroptosis · Necroinflammation . Receptor-interacting protein kinase $3 \cdot$ Mixed lineage kinase domain-like - Gasdermin - Apoptosis .

Acute kidney injury-chronic kidney disease transition

\begin{abstract}
Renal tubules represent an intercellular unit and function as a syncytium. When acute tubular necrosis was first visualized to occur through a process of synchronized regulated necrosis (SRN) in handpicked primary renal tubules, it became obvious that SRN actually promotes nephron loss. This realization adds to our current understanding of acute kidney injury (AKI)-chronic kidney disease (CKD) transition and argues for the prevention of AKI episodes to prevent CKD progression. Because SRN is triggered by necroptosis and executed by ferroptosis, 2 recently identified signaling pathways of regulated necrosis, a combination therapy employing necrostatins and ferrostatins may be beneficial for protection against nephron loss. Clinical trials in AKI and during the pro-
\end{abstract}

\section{KARGER}

(C) 2018 S. Karger AG, Basel

E-Mail karger@karger.com

www.karger.com/nef cess of kidney transplantation are now required to prevent SRN. Additionally, necrotic cell death drives autoimmunity and necroinflammation and therefore represents a therapeutic target even for the prevention of antibody-mediated rejection of allografts years after the transplantation process.

ㄷ) 2018 S. Karger AG, Basel

\section{The Caspase-Controlled Cell Death System}

\section{Apoptosis}

It is beyond the scope of this review to refer to the data published on apoptosis in acute kidney injury (AKI). The interested reader is referred to a recent review in which

Contribution from the AKI and CRRT 2018 Symposium at the 23rd International Conference on Advances in Critical Care Nephrology, Manchester Grand Hyatt, San Diego, CA, USA, February 26-March 1, 2018. This symposium was supported in part by the NIDDK funded University of Alabama at Birmingham-University of California San Diego O'Brien Center for Acute Kidney Injury Research (P30DK079337). 
Box 1. Open questions on regulated cell death in AKI

How does the type of cell death relate to the intensity of AKI?

For a single cell, it is hard to reason that it matters how exatly it dies. However, it does matter for the surrounding tissue and the inflammatory response. In the concept of necroinflammation, different cell death pathways are immunogenic to a different extent. Whereas apoptosis does not cause and immune response, pathways of regulated necrosis may initiate a detrimental immune cell infiltrate that further deteriorates the primary damage [8]. The second wave of death may also be dependent on necrosis and thereby fuel a vicious circle of necroinflammation [13].

\section{Is there a role for apoptosis in AKI?}

Despite the work of decades, it is still unclear if apoptosis has a role in human AKI. Clearly, Bax/BAK-dko mice are protected from ischemic [14] AKI and unilateral uretric obstruction [15]. However, the pan-caspase inhibitor zVAD-fmk did not protect mice a model of ischemia-reperfusion injury in our hands [16]. In theory, the presense of an immune cell infiltration that contains NK cells, T cells and neutrophils might argue towards a necroinflammatory component.

Can autoimmunity be explained by failure to remove necrotic cellular debris?

Failure to remove necrotic debris by a process referred to as LC3-associated phagocytosis (LAP) continuously stimulates the immune system, results in the generation of anti-nuclear antibodies (ANAs) and antibodies against double-stranded DNA (ds-DNA antibodies) and drives autoimmunity. [17, 18]. This may not exclusively be the case for systemic lupus erythematosus (SLE), but also for other autoimmune diseases. One such example that causes AKI may be ANCA-associated vasculitis [19].

we discussed this topic in detail [1]. Along these lines, the caspase-controlled cell death system also includes pyroptosis, a pathway that results in necrotic cell death downstream of inflammasomes activation. This format does not allow us to review this pathway in detail, as it has not been investigated in AKI yet. However, recent data suggest that it might be very important in AKI-chronic kidney disease (CKD) progression [2].

\section{Necroptosis}

Necroptosis is an evolutionary conserved pathway of regulated necrosis $(\mathrm{RN})$ to defend viruses that express caspase inhibitors. Caspase- 8 controls the protein receptor-interacting protein kinase 3 (RIPK3), the only known serin-theronine kinase that can phosphorylate the necroptosis executing pseudokinase MLKL (mixed lineage kinase domain-like). pMLKL, by unknown means that involve the ESCRT-III complex [3], results in plasma membrane rupture. With respect to AKI, RIPK3-deficient mice [4] and MLKL-deficient mice [5] are protected from renal ischemia-reperfusion injury. Inhibition of necroptosis, therefore, appears to be a promising therapeutic target, but highly specific kinase inhibitors of RIPK1 (Nec-1s, ponatinib) did not protect from IRI in our hands (A.L., unpublished data). Obviously, there is a combination of several pathways of $\mathrm{RN}$ and its relative contribution to the overall organ damage of AKI is unclear today.

It has recently been confirmed that the active production of cytokines occurs during necroptosis progression
[6], but precise mechanisms are incompletely understood. However, the prevention of necroptosis signaling by necrostatins should prevent the release of immune modifying cytokines, but it remains unclear if necrostatins affect CD8+ T-cell cross priming [7]. If RN-pathways specifically shape the immune response, a novel hypothesis emerges and we refer to it as necroinflammation [8]. Box 1 summarizes the most important open questions with respect to necroinflammation during AKI.

\section{The Lipid Peroxidation/Autoxation-Controlled Necrosis System}

\section{Ferroptosis}

Ferroptosis is an iron-dependent cell death pathway that involves specific lipid peroxidation patterns that are involved in plasma membrane rupture [9]. However, the precise mechanisms of how lipid peroxidation actually causes the membrane to disintegrate are elusive. Importantly, the glutathione (GSH) peroxidase 4 (GPX4) routinely prevents ferroptosis and lipid peroxidation, specifically of a recently identified phosphatidylethanolamine residue (see below).

Ferroptosis has first been described in renal tubules that no longer underwent necrotic transformation upon addition of a second generation ferrostatins [10]. This led to the investigation of third-generation ferrostatins that were identified in screening approaches on small molecules. These small molecules are stable in vivo and there- 
fore facilitated the assessment of ferroptosis-interference in vivo in models of AKI. In our hands, the ferrostatins 16-86 was the most potent single compound to preserve the renal structure and function in a model of severe ischemia-reperfusion injury [11]. Strikingly, the mode of necrotic cell death strongly mimics the cellular changes observed in urine sediments upon acute tubular necrosis. In handpicked isolated perfused renal tubules, the addition of ferroptosis-inducing agents (erastin) resulted in an intercellular chain reaction that we referred to as synchronized RN (SRN) [11]. It is now clear that ferroptosis drives this reaction, and in vitro models are being developed. In parallel, the importance of ferroptosis in AKI was confirmed by the genetic depletion of GPX4 in renal tubules that resulted in lethal tubular necrosis that was sensitive to the application of a ferrostatins [12]. GPX4 is a selenocysteine-containing protein (a selenoprotein) and the prevention of ferroptosis may explain the need for selenium uptake of humans. Clearly, the renal tubular system is among the most ferroptosis-sensitive parenchymal structures in the human body. However, as tempting as ferroptosis may exhibit a model for nephron loss, from an evolutionary perspective, it is not immediately clear why humans should conserve an RN-pathway of synchronized necrosis (SRN) as an evolutionary benefit. In this respect, ferroptosis may better be interpreted as a failsafe rather than an $\mathrm{RN}$ pathway. Importantly, life on earth requires a system to inactivate highly reactive oxygen and reactive oxygen species, especially in cells with high ATP turnover. In this sense, failure to appropriately cope with the ROS load may result in ferroptosis.

Hardly anything is known about the immunogenicity of ferroptosis. As short lived lipid peroxides are highly toxic (possibly explaining the phenomenon of SRN), they might even kill infiltrating lymphocytes or other immune cells. In addition, it is not clear how a wave of SRN might be terminated mechanistically. However, ferroptosis was only recently described and is certainly under intense investigation.

\section{Conclusions and Outlook}

It remains a major task to unravel the relative contribution of $\mathrm{RN}$ pathway to the overall organ damage during AKI. Several complicating factors need to be overcome. First, the in vivo models of AKI used today hardly reflect the situation of AKI on an ICU or in multimorbid patients. Second, our biomarkers of AKI and necroinflammation are insufficient. A biomarker panel is needed - not only a damage marker or only a functional marker. Third, inhibitors of necroptosis are in clinical trials for autoimmune conditions, but clear AKI trials remain to be initiated. Ferrostatins, to the best of our knowledge, have not passed phase 1 clinical trials so far. Finally, the clinically used AKIN and/or KDIGO classifications were not correlated with long-term outcome of AKI patients and hardly represent reliable gold standards for clinical comparison.

\section{Acknowledgments}

Work in the Linkermann Lab is funded by the Medical Clinic 3, University Hospital Carl Gustav Carus Dresden, Germany, and supported by the SFB-TRR 205, SFB-TRR 127, and the international research training group (IRTG) 2251. W.T. is supported by the SFBTRR 205. A.L. is supported by a Heisenberg-Professorship granted by the German Research Foundation (DFG). We like to thank all members of the Linkermann Lab for continuous discussions.

\section{Disclosure Statement}

The authors declare that there are no conflicts of interest.

\section{References}

1 Linkermann A, Chen G, Dong G, Kunzendorf U, Krautwald S, Dong Z: Regulated cell death in AKI. J Am Soc Nephrol 2014;25:26892701.

2 Komada T, Chung H, Lau A, Platnich JM, Beck PL, Benediktsson H, Duff HJ, Jenne $\mathrm{CN}$, Muruve DA: Macrophage uptake of necrotic cell DNA activates the AIM2 inflammasome to regulate a proinflammatory phenotype in CKD. J Am Soc Nephrol 2018; 29:1165-1181.

3 Gong YN, Guy C, Olauson H, Becker JU, Yang M, Fitzgerald P, Linkermann A, Green
DR: ESCRT-III acts downstream of MLKL to regulate necroptotic cell death and its consequences. Cell 2017;169:286-300.e216.

4 Linkermann A, Brasen JH, Darding M, Jin MK, Sanz AB, Heller JO, De Zen F, Weinlich R, Ortiz A, Walczak H, Weinberg JM, Green DR, Kunzendorf U, Krautwald S: Two independent pathways of regulated necrosis mediate ischemia-reperfusion injury. Proc Natl Acad Sci U S A 2013;110:1202412029.

5 von Massenhausen A, Tonnus W, Himmerkus N, Parmentier S, Saleh D, Rodriguez
D, Ousingsawat J, Ang RL, Weinberg JM, Sanz AB, Ortiz A, Zierleyn A, Becker JU, Baratte B, Desban N, Bach S, Schiessl IM, Nogusa S, Balachandran S, Anders HJ, Ting AT, Bleich M, Degterev A, Kunzelmann K, Bornstein SR, Green DR, Hugo C, Linkermann A: Phenytoin inhibits necroptosis. Cell Death Dis 2018;9:359.

6 Zhu K, Liang W, Ma Z, Xu D, Cao S, Lu X, Liu N, Shan B, Qian L, Yuan J: Necroptosis promotes cell-autonomous activation of proinflammatory cytokine gene expression. Cell Death Dis 2018;9:500. 
7 Yatim N, Jusforgues-Saklani H, Orozco S, Schulz O, Barreira da Silva R, Reis e Sousa C, Green DR, Oberst A, Albert ML: RIPK1 and NF-kappaB signaling in dying cells determines cross-priming of CD8+ T cells. Science 2015;350:328-334.

8 Sarhan M, Land WG, Tonnus W, Hugo CP, Linkermann A: Origin and consequences of Necroinflammation. Physiol Rev 2018;98:727780.

9 Stockwell BR, Friedmann Angeli JP, Bayir H, Bush AI, Conrad M, Dixon SJ, Fulda S, Gascon S, Hatzios SK, Kagan VE, Noel K, Jiang X, Linkermann A, Murphy ME, Overholtzer M, Oyagi A, Pagnussat GC, Park J, Ran Q, Rosenfeld CS, Salnikow K, Tang D, Torti FM, Torti SV, Toyokuni S, Woerpel KA, Zhang DD: Ferroptosis: a regulated cell death nexus linking metabolism, redox biology, and disease. Cell 2017;171:273-285.

10 Skouta R, Dixon SJ, Wang J, Dunn DE, Orman M, Shimada K, Rosenberg PA, Lo DC, Weinberg JM, Linkermann A, Stockwell BR: Ferrostatins inhibit oxidative lipid damage and cell death in diverse disease models. J Am Chem Soc 2014;136:4551-4556.

11 Linkermann A, Skouta R, Himmerkus N, Mulay SR, Dewitz C, De Zen F, Prokai A, Zuchtriegel G, Krombach F, Welz PS, Weinlich R, Vanden Berghe T, Vandenabeele P,
Pasparakis M, Bleich M, Weinberg JM, Reichel CA, Brasen JH, Kunzendorf U, Anders HJ, Stockwell BR, Green DR, Krautwald S: Synchronized renal tubular cell death involves ferroptosis. Proc Natl Acad Sci U S A 2014;111:16836-16841.

12 Friedmann Angeli JP, Schneider M, Proneth B, Tyurina YY, Tyurin VA, Hammond VJ, Herbach N, Aichler M, Walch A, Eggenhofer E, Basavarajappa D, Radmark O, Kobayashi S, Seibt T, Beck H, Neff F, Esposito I, Wanke R, Forster $\mathrm{H}$, Yefremova $\mathrm{O}$, Heinrichmeyer M, Bornkamm GW, Geissler EK, Thomas SB, Stockwell BR, O’Donnell VB, Kagan VE, Schick JA, Conrad M: Inactivation of the ferroptosis regulator Gpx4 triggers acute renal failure in mice. Nat Cell Biol 2014;16:11801191.

13 Martin-Sanchez D, Fontecha-Barriuso M, Carrasco S, Sanchez-Niño MD, Mässenhausen Av, Linkermann A, Cannata-Ortiz P, Ruiz-Ortega M, Egido J, Ortiz A, Sanz AB: TWEAK and RIPK1 mediate a second wave of cell death during AKI. Proc Natl Acad Sci U S A 2018;115:4182-4187.

14 Wei Q, Dong G, Chen JK, Ramesh G, Dong Z: Bax and Bak have critical roles in ischemic acute kidney injury in global and proximal tubule-specific knockout mouse models. Kidney Int 2013;84:138-148.
15 Mei S, Li L, Wei Q, Hao J, Su Y, Mei C, Dong $\mathrm{Z}$ : Double knockout of Bax and Bak from kidney proximal tubules reduces unilateral urethral obstruction associated apoptosis and renal interstitial fibrosis. Sci Rep 2017;7:44892.

16 Linkermann A, Brasen JH, Himmerkus N, Liu S, Huber TB, Kunzendorf U, Krautwald S: Rip1 (receptor-interacting protein kinase 1) mediates necroptosis and contributes to renal ischemia/reperfusion injury. Kidney Int 2012; 81:751-761.

17 Martinez J, Cunha LD, Park S, Yang M, Lu Q, Orchard R, Li QZ, Yan M, Janke L, Guy C, Linkermann A, Virgin HW, Green DR: Noncanonical autophagy inhibits the autoinflammatory, lupus-like response to dying cells. Nature 2016;533:115-119.

18 Martinez J, Malireddi RK, Lu Q, Cunha LD, Pelletier S, Gingras S, Orchard R, Guan JL, Tan H, Peng J, Kanneganti TD, Virgin HW, Green DR: Molecular characterization of LC3-associated phagocytosis reveals distinct roles for Rubicon, NOX2 and autophagy proteins. Nat Cell Biol 2015;17:893-906.

19 Schreiber A, Rousselle A, Becker JU, von Massenhausen A, Linkermann A, Kettritz R: Necroptosis controls NET generation and mediates complement activation, endothelial damage, and autoimmune vasculitis. Proc Natl Acad Sci U S A 2017;114:E9618-E9625. 